\title{
Unlicensed and off-label prescription of respiratory drugs to children
}

\author{
G.W. 't Jong*,\#, I.A. Eland" ${ }^{\#}$, M.C.J.M. Sturkenboom ${ }^{\#, \uparrow}$, J.N. van den Anker ${ }^{*,+, \S}$, B.H.C. Stricker ${ }^{\#, f}$
}

Unlicensed and off-label prescription of respiratory drugs to children. G. W. 't Jong, I.A. Eland, M.C.J.M. Sturkenboom, J.N. van den Anker, B.H.C. Stricker. (C)ERS Journals Ltd 2004.

ABSTRACT: Many respiratory drugs are not available in formulations suitable for infants and toddlers. Efficacy and safety research is mostly restricted to older children. However, respiratory drugs are frequently used in children for common diseases like asthma, upper and lower respiratory tract infections, rhinitis and sinusitis. The unlicensed and off-label use of respiratory drugs in children were studied.

A population-based cohort study was conducted by using the computerised medical records in the Integrated Primary Care Information project. The study population comprised a random sample from all children aged 0 - 16 yrs who were registered with a general practitioner in 1998. All prescriptions for respiratory drugs during the study period were classified according to their licensing and off-label status.

The study population comprised 13,426 patients $(51.7 \%$ male, median age 8.7 yrs), of whom $2,502(19 \%)$ received 5,253 prescriptions for respiratory drugs in 1998 . A total of $3,306(62.9 \%)$ prescriptions concerned licensed drugs. Of the remaining 1,947 prescriptions $(37.1 \%), 882(16.8 \%)$ were unlicensed for use in children, and 1,065 $\mathbf{2 0 . 3} \%)$ were prescribed off-label. The 1-yr cumulative risk of receiving an unlicensed or off-label prescription was $\mathbf{4 5} \%$ among children with at least one prescription for a respiratory drug.

This population-based study showed that a large proportion of respiratory drugs prescribed by the general practitioner are unlicensed for use in children, or licensed but prescribed in an off-label manner. Results have to be interpreted with caution because they may unjustly suggest inaccurate prescribing, whereas it may be difficult to treat children with respiratory symptoms and diseases, because for many respiratory drugs paediatric data on safety and efficacy are insufficient. These findings underline the importance of research on suitable formulations, dosages and efficacy of respiratory drugs in children.

Eur Respir J 2004; 23: 310-313.
*Dept of Paediatrics, Sophia Children's Hospital, "Pharmacoepidemiology Unit, Depts of Epidemiology and Biostatistics and Internal Medicine, Dept of Medical Informatics, Erasmus University Medical Centre, Rotterdam, and ${ }^{f}$ Drug Safety Unit, Inspectorate for Health Care, The Hague, the Netherlands. ${ }^{+}$Division of Pediatric Clinical Pharmacology, Children's National Medical Center, and ${ }^{\S}$ Depts of Pediatrics and Pharmacology, The George Washington University, Washington DC, USA.

Correspondence: B.H.C. Stricker, Dept of Epidemiology \& Biostatistics, Erasmus Medical Centre Rotterdam, PO Box 1738, 3000 DR Rotterdam, the Netherlands.

Fax: 31104089382

E-mail: b.stricker@erasmusmc.nl

Keywords: Children, drug use, epidemiology, off-label, respiratory, unlicensed

Received: February 112003

Accepted after revision: September 262003

This work was supported by the Sophia Foundation for Scientific Research through a research grant (SSWO project no. 293).
The extent and nature of unlicensed and off-label drug prescription in paediatric clinical care has been the subject of several surveys in Europe [1-7] and these consistently showed that a very large proportion of prescribed drugs are either unlicensed for use in children or used outside the terms of the product license ("off-label"). Several studies also provide information on the extent of this type of drug prescription in children with respiratory diseases, but information provided is often limited.

Respiratory drugs are used for several of the most common paediatric diseases such as asthma, upper and lower respiratory tract infections, rhinitis and sinusitis; conditions that are treated in general practice rather than in clinical care [8-12]. Previous research by the present group revealed that $70 \%$ of available respiratory drugs in the Netherlands are not fully licensed for use in children, and many of these $(80 \%)$ are registered only for specific age/weight groups [13]. Many of the children with respiratory problems present themselves long before they have reached the age range given in the product information of many respiratory drugs. As part of a larger project [14], a large cohort study was conducted in general practice to assess the extent and nature of unlicensed and off-label prescription of respiratory drugs in children.

\section{Methods}

\section{Setting}

All data were retrieved from the Integrated Primary Care Information (IPCI) project, a longitudinal observational database with data from computer-based patient records from a group of 150 general practitioners (GPs) in the Netherlands. As of 2001, the IPCI database contains data on a cumulative number of 485,000 patients. The system complies with European Union guidelines on the use of medical data for medical research and has been proven valid for pharmacoepidemiological research [15].

\section{Design}

A population-based cohort study was conducted in a dynamic population of children in the IPCI database who were permanently registered with one of the participating general practices between 1 January 1998 and 31 December 1998 [14]. In 1998, 53,702 children were registered in the IPCI database. Since this research required manual review of all prescriptions $25 \%$ were randomly sampled from the population, 
which formed the primary study population $(n=13,426)$. All study subjects were followed from 1 January 1998, or the date of registration in the GP practice, whichever was latest, until the earliest of one of the following censoring points: death, reaching the age of $17 \mathrm{yrs}$, transferring out of the practice, or end of the study period.

\section{Classification of prescriptions}

From the prescription file, all prescriptions plus their dosage regimens and indications issued to the primary study population in 1998 were extracted. Respiratory drugs were categorised into "nasal preparations" (ATC R01), "oropharyngeal preparations" (ATC R02), "antiasthmatics" (ATC R03), "cough and cold medications" (ATC R05) and "antihistamines for systemic use" (ATC R06).

All prescriptions for respiratory drugs were classified regarding their licensing status [3]. The main mutually exclusive categories were: 1) licensed for children; 2) licensed, but used off-label; and 3) unlicensed for children. Further classification of prescriptions was performed as described earlier [14]. As a reference source for classification, the official product license was used, as approved by the Dutch Medicines Evaluation Board and the European Medicines Evaluation Agency (EMEA).

Age was classified in line with the paediatric age definitions provided by the EMEA [16], but the category $2-<12$ yrs was split because of heterogeneity within this age group [17]. Age groups used were: $0-<1$ month, 1 month $-<2$ yrs, $2-<6$ yrs, $6-<12$ yrs, and $\geqslant 12$ years. Since the number of prescriptions in the youngest age group was negligible $(n=1)$, this group was excluded from further analysis.

\section{Analysis}

Descriptive analyses were conducted for patient demographics, prescription data and outcome. Statistical comparisons consisted of independent unpaired t-tests for continuous variables, and Chi-squared tests for discrete variables. Confidence intervals (CI) of 95\% around prevalence estimates were based on the normal distribution.
Table 1.-Characteristics of study population

\begin{tabular}{lcc}
\hline Variable & $\begin{array}{c}\text { Respiratory drug } \\
\text { prescription-receiving } \\
\text { children }\end{array}$ & $\begin{array}{c}\text { Drug } \\
\text { prescription-receiving } \\
\text { children }\end{array}$ \\
\hline Subjects & 2502 & 6313 \\
Male & $1318(52.7)$ & $3066(48.6)$ \\
Female & $1184(47.3)$ & $3247(51.4)$ \\
Age groups & & \\
$\quad 0-<1$ month & $1(<0.1)$ & $40(0.6)$ \\
1 month-<2 yrs & $821(32.6)$ & $1263(20.0)$ \\
$2-<6$ yrs & $947(37.8)$ & $1797(28.5)$ \\
$6<12$ yrs & $833(33.3)$ & $1921(30.4)$ \\
$\geqslant 12$ yrs & $552(22.0)$ & $1562(24.7)$ \\
\hline
\end{tabular}

Data are presented as $\mathrm{n}(\%)$ unless otherwise stated. Percentage is calculated based on column total. \#: totals do not add up to the total of the study group, since some patients contributed to several age groups; : all drug prescriptions over 1998 , including respiratory drugs.

\section{Results}

During the study period, 5,253 prescriptions concerning respiratory drugs were issued to 2,502 patients (table 1). The median number of respiratory drug prescriptions among respiratory drug-using children was 1 (interquartile range (IQR) 1-2). The median number of prescriptions was 2 per patient per year (IQR 1-3) for antiasthmatics. Patients who received respiratory drugs were significantly younger than the rest of the study population $(\mathrm{p}<0.001)$.

The most frequently prescribed respiratory drugs were antiasthmatics (40.7\% of all prescriptions), followed by systemic antihistamines $(27.7 \%)$ and nasal preparations $(23.2 \%)$. Largest subclasses of drugs (in numbers of prescriptions) were corticosteroids $(18.0 \%)$, selective $\beta_{2}$-sympathomimetics $(17.1 \%)$, systemic antihistamines $(14.8 \%)$, sympathomimetics for nasal use $(12.7 \%)$ and phenothiazine derivates $(8.9 \%)$, as shown in table 2 . The most frequently prescribed drugs were salbutamol $(12.7 \%)$, xylomethazoline $(12.7 \%)$, promethazine $(7.4 \%)$, beclomethasone $(6.5 \%)$ and fluticasone $(6.5 \%)$.

Of the 5,252 prescriptions, 3,305 (62.9\%) were licensed for use in children, and prescribed in concordance with the product license. Of the remaining 1,947 prescriptions $(37.1 \%)$,

Table 2. - Respiratory drug utilisation

\begin{tabular}{|c|c|c|c|c|c|c|c|c|c|c|c|}
\hline \multirow[t]{2}{*}{ Drug class } & \multirow[t]{2}{*}{ Drug category } & \multicolumn{6}{|c|}{ Prescriptions } & \multicolumn{4}{|c|}{ Users } \\
\hline & & Total & $\%{ }^{\#}$ & $\mathrm{UL}$ & $\%$ & $\mathrm{OL}$ & $\%$ & Total & $\%$ & $\mathrm{UL} / \mathrm{OL}^{+}$ & $\%$ \\
\hline Inhaled corticosteroids & Antiasthmatics & 943 & 18.0 & & & 307 & 32.6 & 488 & 3.6 & 180 & 36.9 \\
\hline Inhaled $\beta_{2}$-sympathomimetics & Antiasthmatics & 898 & 17.1 & 162 & 18.0 & 300 & 33.4 & 561 & 4.2 & 318 & 56.7 \\
\hline Indifferent antihistamines ${ }^{\S}$ & Antihistamines for systemic use & 776 & 14.8 & 299 & 38.5 & 49 & 6.3 & 517 & 3.9 & 267 & 51.6 \\
\hline Nasal sympathomimetics & Nasal preparations & 668 & 12.7 & 32 & 4.8 & 9 & 1.3 & 602 & 4.5 & 37 & 6.1 \\
\hline Pheothiazine derivates & Antihistamines for systemic use & 467 & 8.9 & 73 & 15.6 & 20 & 4.3 & 389 & 2.9 & 78 & 20.1 \\
\hline Nasal corticosteroids & Nasal preparations & 276 & 5.3 & 141 & 51.1 & 4 & 1.4 & 182 & 1.4 & 94 & 51.6 \\
\hline Nonsteroid antiallergic drugs & Nasal preparations & 200 & 3.8 & 119 & 59.5 & 4 & 2.0 & 120 & 0.9 & 75 & 62.5 \\
\hline Piperazine derivates & Antihistamines for systemic use & 175 & 3.3 & 15 & 8.6 & 7 & 4.0 & 119 & 0.9 & 15 & 12.6 \\
\hline Opium alkaloids and derivates & Cough and cold medications & 164 & 3.1 & 1 & 0.6 & 26 & 15.9 & 141 & 1.1 & 25 & 17.7 \\
\hline Parasympathomimetics & Antiasthmatics & 112 & 2.1 & 7 & 6.3 & 100 & 89.3 & 88 & 0.7 & 84 & 95.5 \\
\hline Expectorants & Cough and cold medications & 98 & 1.9 & 34 & 34.7 & 20 & 20.4 & 93 & 0.7 & 74 & 79.6 \\
\hline Mucolytics $^{f}$ & Cough and cold medications & 81 & 1.5 & & & 28 & 34.6 & 71 & 0.5 & 26 & 36.6 \\
\hline Other drugs for nasal use $\mathrm{e}^{\# \#}$ & Nasal preparations & 75 & 1.4 & & & & & 57 & 0.4 & & \\
\hline Other cough-suppressant drugs ${ }^{\text {ศथ }}$ & Cough and cold medications & 75 & 1.4 & & & 52 & 69.3 & 61 & 0.5 & 44 & 72.1 \\
\hline $\begin{array}{l}\text { Sympathomimetics+other } \\
\text { antiasthmatics }\end{array}$ & Antiasthmatics & 69 & 1.3 & & & 68 & 98.6 & 50 & 0.4 & 50 & 100.0 \\
\hline
\end{tabular}

UL: unlicensed; OL: off-label. ${ }^{\#}$ : percentage of total number of respiratory prescriptions $(\mathrm{n}=5252)$ and patients in the cohort $(\mathrm{n}=13426)$; ${ }^{\top}$ row percentage; ${ }^{+}$: patients with an UL or OL prescription; ${ }^{\S}$ : e.g. deptropine, ketotifen, and tefenadine; ${ }^{\circ}$ : acetylcysteine and brome hexin; ${ }^{\prime \prime \#}$ : e.g. mupirocin and $\mathrm{NaCl}$; ${ }^{\uparrow}$ e.g. pentoxyverine; ${ }^{++}$: e.g. fenoterol+ipratropium in Berodual $($R. 
Table 3.-Number of drug prescriptions within licensing status

\begin{tabular}{lrr}
\hline Variable & $\begin{array}{c}\text { Unlicensed/ } \\
\text { off-label }\end{array}$ & Licensed \\
\hline Age groups & & \\
1 month $<2$ yrs & $644(65.2)$ & $343(34.8)$ \\
$2<6$ yrs & $583(35.2)$ & $1074(64.8)$ \\
$6<12$ yrs & $422(27.9)$ & $1089(72.1)$ \\
$\geqslant 12$ yrs & $298(27.2)$ & $799(72.8)$ \\
Drug classes & $1008(47.1)$ & $1131(52.9)$ \\
$\quad$ Antiasthmatics & $466(32.0)$ & $991(68.0)$ \\
Antihistamines for systemic use & $309(25.3)$ & $910(74.7)$ \\
$\quad$ Nasal preparations & $162(38.1)$ & $263(61.9)$ \\
Cough and cold medication & $2(15.4)$ & $11(84.6)$ \\
$\quad$ Oropharyngeal preparations & $1947(37.1)$ & $3305(62.9)$ \\
Total &
\end{tabular}

Data are presented as $\mathrm{n}(\%)$. The percentages are within age group/drug class.

$882(16.8 \%, 95 \%$ CI 15.8-17.8) were prescriptions for unlicensed drugs, and 1,065 $(20.3 \%, 95 \%$ CI 19.2-21.4) were off-label prescriptions for licensed drugs. Unlicensed drugs consisted of modification of preparations $(8.7 \%)$, drugs that lacked information on use in children $(6.6 \%)$, and drugs that were contraindicated for use $(1.4 \%)$. Prescriptions were off-label for age $(7.3 \%)$, dose $(7.8 \%)$, frequency $(3.8 \%)$, indication $(4.5 \%)$ or dosage form $(1.1 \%)$. Drugs could be off-label for several reasons. Unlicensed and off-label drug use differed for the various respiratory drug classes (table 2). Off-label use was especially high for antiasthmatic drugs (39\%), and cough and cold medication $(30 \%)$. Antiasthmatic drugs were frequently off-label for dose and/or indication or age/weight (14, 10 and $15 \%$, respectively), and cough and cold medication was mostly off-label for dose $(19 \%)$. Unlicensed use was especially high for nose preparations and antihistamines for systemic use (24.0 and $26.4 \%$, respectively), but off-label use was very low in these groups; the primary reason for unlicensed drug use for both drug classes was modification of preparations by the pharmacy. The most frequently prescribed unlicensed and off-label drugs were salbutamol (inhaled, off-label for age and dose), deptropine (syrup, unlicensed), fluticasone (inhaled, off-label for dose), terbutaline (inhaled, off-label for dose), and sodium cromoglycate (nasal spray, no information on use in children).

The numbers of unlicensed and off-label prescriptions were highest in the age group 1 month $-<2$ yrs (table 3 ). The $1-y r$ cumulative risk of an unlicensed or off-label prescription was $45 \%$ (95\% CI 43-47) among children with at least one prescription for a respiratory drug. Males had a $15 \%(95 \% \mathrm{CI}$ 6-25) higher chance of receiving unlicensed or off-label prescriptions for antiasthmatics than females. For other groups no significant differences were found.

For some infrequently used drugs (parasympathomimetics and expectorants), the percentage of exposed children with at least one off-label or unlicensed prescription was highest $(95$ and $79 \%$, respectively). However, the percentage of children with at least one off-label or unlicensed prescription was also high among the drugs with the highest exposure (table 2).

\section{Discussion}

This study showed a high 1-yr cumulative risk of unlicensed and off-label use of respiratory drugs among children who use these drugs. In terms of prescription, $17 \%$ were unlicensed and $20 \%$ off-label. The risk of at least one off-label or unlicensed prescription was highest among users of parasympathometics, expectorants, sympathomimetics for inhalation and systemic antihistamines, and was highest for young children.

These high numbers of unlicensed and off-label drug use, however, have to be interpreted with caution because they may unjustly suggest inaccurate prescribing. In fact, there is a lack of properly licensed drugs for all age groups in dosage forms that are suitable, and with dosing windows that correspond to the needs regarding symptom relief and cure of patients. Another reason for a cautious interpretation is the fact that there may be a difference between the product information and prescribing guidelines, such as given by the Dutch College of General practitioners and in formularies like the Physician's Desk Reference [18], and the British National Formulary or the Medicines for Children formulary [19]. Therefore, not all deviations from the product information can be qualified as errors. However, the licensing information text of many respiratory drugs provides physicians with dosage recommendations that are more restricted than the information text in common drug formularies, which also contain data that are based on experience, and not so much on evidence.

The high percentage of modified preparations for children $(8.7 \%)$ is a direct result of the lack of licensed paediatric formulations $[20,21]$, which requires modification of commercial preparations in the pharmacies. The drug prescriptions that were off-label for age were not checked for other off-label categories like indication and dosage, since these were not provided in the labelling information text. The dosage form therefore seems to be correct for most prescriptions, but especially in the younger children, the availability of suitable formulations is limited. Although there have been major advances in relation to different types of inhalers for children of different ages with asthma, such as the turbohaler, nebuhaler and volumatic inhaler [22], knowledge of reproducibility of dose and lung disposition is limited [23]. Pressurised metered dose inhalers/spacers and face masks are needed for these children [24], and parents have to be adequately instructed to be able to apply the drug. Dose variability for these drugs in small infants is large, and increased by complicating factors like bad cooperation by the wheezy infant [25].

Earlier research on unlicensed and off-label respiratory drug use in general practice in children is scarce, except for a study in the UK [26] that reported individual percentages of unlicensed and off-label use for some respiratory drugs. However, this study group was small, since only one GP participated. Besides, the classification system used by MCINTYRE et al. [26] for unlicensed and off-label status of drugs differs from the system that was used for this study.

A recent study in the Netherlands based on pharmacy dispensing records showed that $15.1 \%$ of prescriptions in that study were off-label, and another $6.4 \%$ unlicensed. Prescriptions by specialists (outpatient), prescriptions for new drugs, prescriptions for drugs with a low use in the paediatric population, and prescriptions for infants were risk factors for using a systemic drug unlicensed or off-label in that study [27]. Since the indications are not available in pharmacy dispensing data, the indication for prescription of a drug was not evaluated. The prescriptions in this study were also not evaluated for dose, frequency, dosage form and route of administration. Therefore, the results show a much lower unlicensed and off-label use of drugs in children. However, the authors acknowledge the risk factors as indicated by this article. Unfortunately, they were unable to differentiate between outpatient specialist prescriptions, continued by the GP, and initial GP prescription.

Several measures have been taken by the Food and Drug Administration (FDA) for the improvement of the current "orphan status" of children regarding drug research. As part 
of the FDA modernisation act, the "Pediatric Exclusivity Provision" was introduced to increase the numbers of paediatric registrations of drugs for children. Six extra months of patent exclusivity (the right to produce and sell a drug) could be obtained when drugs were issued for paediatric licensing. However, instead of intensified research on drugs most useful for the paediatric population, such as sympathicomimetics, and corticosteroids for respiratory use, many of the Written Requests that were issued for this 6-month exclusivity were cardiovascular drugs and other drugs that are rarely prescribed in the paediatric population but for which an extra 6 months of exclusivity is very lucrative in adults [28].

Although this study has been conducted in the Netherlands, where the healthcare system differs from many other European countries, results are relevant to Europe as well. Other studies have shown high frequency of unlicensed and off-label drug use for other European countries [29-32], and the labelling of drugs is equal or highly similar due to the increasing role of the European registration authority during the last decade. Most importantly, the conclusion that has to be drawn regarding the licensing of respiratory drugs in children concerns the Netherlands as well as all other countries.

Results show the high use of unlicensed and off-label use of respiratory drugs in children, while these are among the most commonly used drugs in children. The current shortage of formulations and dosage forms appropriate for infants and toddlers, especially, has to be resolved, and research on new and older drugs should include safety and efficacy studies in all appropriate paediatric age groups. Postmarketing surveillance of paediatric drug use should be intensified in order to increase the knowledge of safety and efficacy in a patient group, for which drug testing is restricted by ethical and practical boundaries.

\section{References}

1. Conroy S, McIntyre J, Choonara I. Unlicensed and off label drug use in neonates. Arch Dis Child Fetal Neonatal Ed 1999; 80: F142-F144.

2. Turner S, Longworth A, Nunn AJ, Choonara I. Unlicensed and off label drug use in paediatric wards: prospective study. BMJ 1998; 316: 343-345.

3. Turner S, Nunn A, Choonara I. Unlicensed drug use in children in the UK. Paediatr Perinat Drug Ther 1997; 2: 52-55.

4. Turner S, Gill A, Nunn T, Hewitt B, Choonara I. Use of "off-label" and unlicensed drugs in paediatric intensive care unit. Lancet 1996; 347: 549-550.

5. Conroy S, Choonara I, Impicciatore P, et al. Survey of unlicensed and off label drug use in paediatric wards in European countries. BMJ 2000; 320: 79-82.

6. 't Jong GW, Vulto AG, de Hoog M, Schimmel KJ, Tibboel D, van den Anker JN. Survey of the use of off-label and unlicensed drugs in a Dutch children's hospital. Pediatrics 2001; 108: 1089-1093.

7. Chalumeau M, Treluyer JM, Salanave B, et al. Off label and unlicensed drug use among french office based paediatricians. Arch Dis Child 2000; 83: 502-505.

8. Olubadewo JO, Ikponmwamba A. Profile of prescription medication in a pediatric population. Drug Intell Clin Pharm 1988; 22: 999-1002.

9. Sanz EJ, Bergman U, Dahlstrom M. Paediatric drug prescribing. A comparison of Tenerife (Canary Islands, Spain) and Sweden. Eur J Clin Pharmacol 1989; 37: 65-68.

10. Thrane N, Sorensen HT. A one-year population-based study of drug prescriptions for Danish children. Acta Paediatr 1999; 88: 1131-1136.

11. Straand J, Rokstad K, Heggedal U. Drug prescribing for children in general practice. A report from the More \& Romsdal Prescription Study. Acta Paediatr 1998; 87: 218224.

12. Madsen H, Andersen M, Hallas J. Drug prescribing among Danish children: a population-based study. Eur $J$ Clin Pharmacol 2001; 57: 159-165.

13. 't Jong GW, Eland IA, Stricker BHC, Anker JN. Information for paediatric use of medicines in a product information compendium. Paediatr Perinat Drug Thera 2001; 4: 148-151.

14. 't Jong GW, Eland IA, Sturkenboom MC, Van Den Anker JN, Stricker BH. Unlicensed and off label prescription of drugs to children: population based cohort study. BMJ 2002; 324: $1313-1314$

15. Vlug AE, van der Lei J, Mosseveld BM, et al. Postmarketing surveillance based on electronic patient records: the IPCI project. Methods Inf Med 1999; 38: 339-344.

16. European Agency for the Evaluation of Medicinal Products, Human Medicines Evaluation Unit. Note for Guidance on Clinical Investigation of Medicinal Products in Children. Committee for Proprietary Medicinal Products. London, 1997.

17. Nahata MC. New regulations for pediatric labeling of prescription drugs. Ann Pharmacother 1996; 30: 10321033.

18. Physician's Desk Reference. 56th Edn. Montvale, Medical Economics, 2001

19. The Royal College of Paediatrics and Child Health. Medicines for Children. Hants, UK, B\&MBC Books Ltd, Direct Books, 1999.

20. Nahata MC. Lack of pediatric drug formulations. Pediatrics 1999; 104: 607-609.

21. Nahata MC. Pediatric drug formulations: challenges and potential solutions. Ann Pharmacother 1999; 33: 247-249.

22. $\mathrm{O}^{\prime}$ Callaghan $\mathrm{C}$, Barry $\mathrm{P}$. Inhalation devices for young children. Paediatr Perinat Drug Ther 1997; 2: 57-65.

23. Janssens HM, Devadason SG, Hop WC, LeSouef PN, De Jongste JC, Tiddens HA. Variability of aerosol delivery via spacer devices in young asthmatic children in daily life. Eur Respir J 1999; 13: 787-791.

24. McCarthy TP. Use of 'Nebuhaler' and face-mask in young asthmatic children. Lancet 1990; 335: 983-984.

25. Janssens HM, Heijnen EM, de Jong VM, et al. Aerosol delivery from spacers in wheezy infants: a daily life study. Eur Respir J 2000; 16: 850-856.

26. McIntyre J, Conroy S, Avery A, Corns H, Choonara I. Unlicensed and off label prescribing of drugs in general practice. Arch Dis Child 2000; 83: 498-501.

27. Schirm E, Tobi H, de Jong-van den Berg LT. Risk factors for unlicensed and off-label drug use in children outside the hospital. Pediatrics 2003; 111: 291-295.

28. 't Jong GW, van den Anker JN, Choonara I. FDAMA's written request list: medicines for children. Lancet 2001; 357: 398.

29. Pandolfini C, Impicciatore P, Provasi D, Rocchi F, Campi R, Bonati M. Off-label use of drugs in Italy: a prospective, observational and multicentre study. Acta Paediatr 2002; 91: 339-347.

30. Gavrilov V, Lifshitz M, Levy J, Gorodischer R. Unlicensed and off-label medication use in a general pediatrics ambulatory hospital unit in Israel. Isr Med Assoc J 2000; 2: 595-597.

31. Avenel S, Bomkratz A, Dassieu G, Janaud JC, Danan C. The incidence of prescriptions without marketing product license in a neonatal intensive care unit. Arch Pediatr 2000; 7 : 143-147.

32. Turner S, Nunn AJ, Fielding K, Choonara I. Adverse drug reactions to unlicensed and off-label drugs on paediatric wards: a prospective study. Acta Paediatr 1999; 88: 965968. 